\title{
Sanificação e eliminação do excesso de líquidos em laranja 'Pêra' minimamente processada
}

\author{
Sanification and removal of excess liquids in minimally processed 'Pêra' oranges
}

Autores | Authors

\section{Marcia Yuriko IUAMOTO}

Universidade de São Paulo (USP) Escola Superior de Agricultura "Luiz de Queiroz"

Departamento de Produção Vegetal Piracicaba/SP - Brasil e-mail:myuriko@gmail.com

\section{*Angelo Pedro JACOMINO}

Universidade de São Paulo (USP) Escola Superior de Agricultura "Luiz de Queiroz"

Departamento de Produção Vegetal Av. Pádua Dias, 11 Caixa Postal 9 CEP: 13418-900

Piracicaba/SP - Brasil e-mail: jacomino@usp.br

\section{Claudia Fabrino Machado} MATTIUZ Aline Priscilla Gomes da SILVA

Universidade de São Paulo (USP) Escola Superior de Agricultura "Luiz de Queiroz"

Departamento de Produção Vegetal Piracicaba/SP - Brasil e-mail: claudiafm@usp.br aline_silva@usp.br

Ricardo Alfredo KLUGE

Universidade de São Paulo (USP) Escola Superior de Agricultura "Luiz de Queiroz"

Departamento de Ciências Biológicas Piracicaba/SP - Brasil e-mail: rakluge@usp.br

Maria Cecília de ARRUDA-PALHARINI

Polo Regional Centro Oeste (APTA/SAA) Bauru/SP - Brasil e-mail: mcarruda@apta.sp.gov.br

\section{Resumo}

As tecnologias empregadas para o processamento mínimo visam à obtenção de produtos frescos, convenientes, com segurança microbiológica e ótima qualidade sensorial. A laranja 'Pêra' é a variedade mais produzida no estado de São Paulo e a mais consumida no Brasil. O objetivo deste trabalho foi determinar a eficiência de métodos de sanificação e de eliminação do excesso de líquidos para o processamento mínimo de laranja 'Pêra', na forma de tiras. As laranjas foram selecionadas, lavadas e descascadas manualmente usando-se tratamento hidrotérmico $\left(50^{\circ} \mathrm{C}\right.$ por 8 minutos). Em seguida, foram cortadas em tiras, acondicionadas em sacos de tela de poliamida e submetidas a métodos de sanificação com diferentes aplicações de cloro e de eliminação do excesso de líquidos. Após a realização dos tratamentos, as tiras foram colocadas em bandejas plásticas (PET) e armazenadas a $5^{\circ} \mathrm{C}$ por 12 dias. A centrifugação por 10 segundos reduziu o acúmulo de líquidos nas bandejas durante o armazenamento refrigerado e manteve a aparência da laranja minimamente processada. A drenagem e a centrifugação aumentaram os níveis de contagem microbiana, mas quando foi usada a sanificação em combinação com esses tratamentos houve redução significativa na microbiota contaminante.

Palavras-chave: Citrus sinensis; Pós-Colheita; Centrifugação; Qualidade microbiológica; Avaliação sensorial.

\section{Summary}

The technologies used for the minimal processing of fruits and vegetables aim to achieve fresh and convenient produce with microbiological safety and optimal sensory quality. The 'Pêra' orange is the variety most produced in São Paulo State, Brazil, and the most widely consumed in Brazil. The purpose of this study was to determine the efficiency of sanification and excess liquid removal methods on the minimal processing of 'Pêra' oranges. The oranges were selected, washed, manually peeled using a hydrothermal treatment $\left(50^{\circ} \mathrm{C}\right.$ for 8 minutes), cut into strips, placed in polyamide bags and then submitted to methods for the sanification with chlorine and removal of excess liquids. After the treatments, the strips were placed in plastic trays (PET) and stored at $5^{\circ} \mathrm{C}$ for 12 days. Centrifugation for 10 seconds reduced the accumulation of liquids in the tray during cold storage and maintained the appearance of the strips. Both drainage and centrifugation increased the microbial count, but when sanification was used in combination with these treatments there was a significant reduction in microbial contamination.

Key words: Citrus sinensis; Postharvest; Centrifugation; Microbiological quality; Sensory evaluation. 


\section{Introdução}

O Brasil é reconhecidamente um grande produtor de frutas cítricas, sendo a laranja 'Pêra' uma das mais cultivadas. O consumo de laranja ocorre tradicionalmente na forma de suco, já que para ser consumida na forma de fruta fresca é necessário que seja descascada e algumas vezes fatiada. Esse tipo de preparo torna-se oneroso para os restaurantes e mercados afins. Uma alternativa para aumentar o consumo como fruta, e não como suco, é o processamento mínimo, o qual possibilita a obtenção de produtos mais convenientes e prontos para o consumo.

Os produtos minimamente processados surgiram para dar resposta a uma nova tendência de consumo e têm tido uma aceitação cada vez maior nos mercados mundiais. As frutas e hortaliças processadas atraem os consumidores que procuram produtos frescos e saudáveis, e que também sejam adequados para o transporte e preparo (SANTOS; OLIVEIRA, 2012).

O processamento mínimo inclui, geralmente, as etapas de seleção da matéria-prima, pré-lavagem, processamento (descascamento e corte), sanificação, enxágue, centrifugação e embalagem (SANTOS et al., 2010). Esse preparo provoca injúrias nos tecidos, em função principalmente do descascamento e do corte e, geralmente, reduz a vida útil do produto. Além disso, o excessivo manuseio favorece a contaminação por microrganismos, enquanto que a liberação de exsudato celular disponibiliza nutrientes para a atividade microbiana. Portanto, a segurança microbiológica de produtos minimamente processados precisa ser garantida em adição à manutenção da qualidade sensorial e nutricional (MARTÍN-DIANA et al., 2007).

As frutas cítricas apresentam comportamento respiratório não-climatérico e baixo metabolismo, o que favorece o seu processamento sem alterações fisiológicas significativas; não apresentam problemas de escurecimento enzimático; a polpa possui baixo $\mathrm{pH}$, o que restringe o desenvolvimento de bactérias patogênicas; e a parte suculenta está contida em vesículas, o que restringe o extravasamento do suco (JACOMINO; ARRUDA, 2008).

O cloro, nas suas várias formas, consiste no sanificante mais utilizado em frutas e hortaliças frescas, sendo amplamente recomendado para diminuir a flora microbiana inicial de vegetais minimamente processados (FRANCIS et al., 2012).

Por sua vez, a centrifugação é uma etapa importante durante o processamento mínimo, como forma de retirar o excesso de líquidos proveniente das etapas de sanificação e enxágue, além dos exsudados celulares resultantes do corte, os quais favorecem o crescimento de fungos e de bactérias (SILVA; GUERRA, 2003).

Este trabalho teve como objetivo determinar os efeitos de métodos de sanificação com cloro e de eliminação do excesso de líquidos para a manutenção da qualidade de laranja 'Pêra' minimamente processada.

\section{Material e métodos}

Laranjas 'Pêra' foram colhidas no estádio de maturação adequado para consumo ao natural e submetidas a beneficiamento cuidadoso em casa de embalagem comercial, de forma a obter laranjas lavadas, selecionadas e sem danos mecânicos. Em seguida, foram transportadas para o Laboratório de Pós-colheita de Produtos Hortícolas do Departamento de Produção Vegetal da Escola Superior de Agricultura "Luiz de Queiroz"/USP, em Piracicaba-SP, onde foram novamente selecionadas, lavadas e sanificadas em solução com $200 \mathrm{mg} \mathrm{L}^{-1}$ de cloro ativo por 20 minutos.

As laranjas foram submetidas à técnica de tratamento hidrotérmico, que consistiu na imersão em água a $50^{\circ} \mathrm{C}$ por 8 minutos, seguida de descascamento manual (ARRUDA et al., 2008). Os frutos sem albedo e sem flavedo foram submetidos a quatro cortes longitudinais de forma a se obterem oito tiras por fruto, sendo que a parte central, contendo a columela, foi descartada. O produto minimamente processado foi acondicionado em sacos de tela de poliamida e submetido aos tratamentos.

Os métodos de sanificação com cloro foram baseados nas recomendações feitas por Donadon et al. (2004), e consistiram em: a) sanificação em solução com $20 \mathrm{mg} \mathrm{L}^{-1}$ de cloro ativo a $5^{\circ} \mathrm{C}$, por 10 minutos, após o corte; b) enxágue em água potável a $5^{\circ} \mathrm{C}$ após o corte para retirada do suco extravasado, seguido de sanificação em solução com $100 \mathrm{mg} \mathrm{L}^{-1}$ de cloro ativo a $5^{\circ} \mathrm{C}$ por 10 minutos, e um segundo enxágue em solução com $10 \mathrm{mg} \mathrm{L}^{-1}$ de cloro ativo a $5^{\circ} \mathrm{C}$. O princípio ativo do sanificante foi o dicloroisocianurato de sódio dihidratado (Sumaveg, Johnson-Diversey Brasil Ltda.).

Os métodos de eliminação do excesso de líquidos foram: a) drenagem em escorredor doméstico por 1 minuto; b) centrífuga doméstica Arno, com velocidade de $760 \times g$, por 5 segundos; c) centrífuga doméstica Arno, com velocidade de $760 \times$ g, por 10 segundos. Foram realizados testes preliminares para determinar a viabilidade do uso da centrífuga doméstica como objeto de estudo. Observou-se que a centrifugação por 5 e 10 segundos permitiu retirar excesso de líquidos sem causar danos visíveis à laranja minimamente processada. O tempo de drenagem de 1 minuto foi estabelecido por ser aquele necessário para se observar redução visível no escorrimento de líquido.

As combinações entre os métodos de sanificação com cloro e os métodos de eliminação de excesso de líquidos resultaram nos tratamentos estudados. Frutos não sanificados e sem eliminação do excesso de líquido foram utilizados como controle. Após a realização dos tratamentos, as laranjas minimamente processadas 
foram acondicionadas em bandejas plásticas rígidas de politereftalato de etileno (PET) e armazenadas em câmara fria a $5^{\circ} \mathrm{C}$ durante 12 dias. As avaliações foram realizadas no dia zero (caracterização) e a cada quatro dias.

O delineamento experimental utilizado foi 0 inteiramente casualizado, em esquema fatorial $9 \times 4$ (nove tratamentos e quatro períodos de análise, incluindo o tempo zero). Cada tratamento foi composto de seis repetições, com $200 \mathrm{~g}$ de laranja minimamente processada em cada bandeja.

Foram realizadas as seguintes análises: a) conteúdo de sólidos solúveis: leitura direta em refratômetro digital (Atago modelo Palete PR-101), utilizando-se suco homogeneizado da repetição, e os resultados expressos em 'Brix (LATIMER JUNIOR, 2012); b) acidez titulável: por meio de titulação potenciométrica com hidróxido de sódio a $0,1 \mathrm{~N}$, até $\mathrm{pH} 8,1$, conforme metodologia descrita por (LATIMER JUNIOR, 2012), sendo os resultados expressos em g de ácido cítrico por $100 \mathrm{~g}$ de polpa (\%); c) ratio: relação entre os teores de sólidos solúveis e acidez titulável (CHITARRA; CHITARRA, 2005); d) teor de ácido ascórbico: uma alíquota de $10 \mathrm{~g}$ de suco foi diluída em $50 \mathrm{~mL}$ de ácido oxálico e titulada com DCFI (2.6 diclorofenol indofenol de sódio) até coloração rosada e contínua por 15 segundos (CARVALHO et al., 1990). Os resultados foram expressos em mg de ácido ascórbico por $100 \mathrm{~g}$ de suco; e) extravasamento de suco: foi determinado pela diferença entre a massa inicial da bandeja com os frutos minimamente processados e a massa da mesma bandeja após a drenagem do suco extravasado durante 30 segundos.

As análises microbiológicas foram realizadas de acordo com os métodos propostos por Silva et al. (2007). A contagem de bactérias lácticas foi realizada por plaqueamento em profundidade utilizando-se o meio de cultura OSA e a confirmação das colônias foi realizada por meio do teste de catalase e coloração Gram, com os resultados expressos em UFC g ${ }^{-1}$. Para a contagem total de microrganismos acidúricos, foi realizado o plaqueamento em superfície, utilizando-se o meio de cultura BDA acidificado, com resultados expressos em UFC g ${ }^{-1}$. A contagem de coliformes totais e a $45^{\circ} \mathrm{C}$ foi realizada por meio da técnica de tubos múltiplos, com resultados expressos em NMP $\mathrm{g}^{-1}$

A análise sensorial de aceitabilidade para o atributo aparência foi realizada utilizando-se escala hedônica de nove pontos, variando de 1 (desgostei muitíssimo) a 9 (gostei muitíssimo). A equipe sensorial foi composta por 30 provadores não treinados (FERREIRA et al., 2000). Essa análise foi realizada imediatamente após o processamento e no quarto dia de armazenamento, visando identificar possível influência dos métodos de eliminação do excesso de líquidos, na aparência da fruta minimamente processada.
Os resultados obtidos foram submetidos à análise de variância pelo teste $\mathrm{F}$ e as médias comparadas pelo Teste Tukey (5\%), utilizando o programa estatístico SANEST.

\section{Resultados e discussão}

As laranjas minimamente processadas em tiras, sanificadas ou não, apresentaram diminuição no teor de sólidos solúveis durante o armazenamento $(P \leq 0,05)$, passando de 9,8 para 9,0 Brix (Figura 1a). Resultados semelhantes foram relatados por Arruda et al. (2011) em laranja 'Pêra' minimamente processada armazenada a $6^{\circ} \mathrm{C}$. No entanto, contrariamente aos resultados relatados no presente trabalho, Del Caro et al. (2004), estudando laranjas 'Shamouti' e 'Salustiana' minimamente processadas e armazenadas a $4^{\circ} \mathrm{C}$, por 12 dias, não observaram alterações significativas nos teores de sólidos solúveis durante o armazenamento.

Os frutos sem sanificação e sem enxágue (T1 a T3) apresentaram os maiores teores de sólidos solúveis na maioria das avaliações. Já os frutos com duplo enxágue, sanificação e drenagem (T7) apresentaram os menores teores. É provável que o maior contato das vesículas de suco com a água, durante o enxágue e a sanitização, associado à elevada relação superfície exposta/volume fez extravasar mais conteúdo celular, incluindo os carboidratos solúveis (componente dos sólidos solúveis) que se dissolveram na água de sanificação. Resultados semelhantes foram encontrados por Vitti et al. (2004), que estudaram o processamento mínimo de beterraba e observaram menores teores de sólidos solúveis nos tratamentos que receberam pelo menos uma sanificação após o corte.

Todos os tratamentos apresentaram redução no teor de acidez titulável ao longo do armazenamento $(P \leq 0,05)$ (Figura 1b). Os tratamentos sem sanificação e sem enxágue (T1 a T3) demonstraram os teores mais elevados com média de 0,42\% de ácido cítrico. Os tratamentos que receberam duas operações de enxágue (T7 a T9) apresentaram os menores teores de AT ao final do armazenamento, com média de 0,34\% de ácido cítrico. Provavelmente, os menores teores de AT nos tratamentos que receberam sanificação e duplo enxágue devem-se à atividade metabólica mais acentuada nesses tratamentos, ocasionada pela maior manipulação durante o processamento mínimo. Segundo Rinaldi et al. (2005), isso pode ter ocorrido pelo maior consumo de ácidos orgânicos e radicais ácidos da parede celular. Outra possibilidade é que o maior contato do produto minimamente processado com a água, devido ao duplo enxágue, fez extravasar mais conteúdo celular, incluindo os ácidos orgânicos, que são hidrossolúveis. Pereira et al. (2014) reportam que em laranja 'Valência Delta' os valores médios de acidez titulável oscilaram entre 0,38 a 0,44\% 

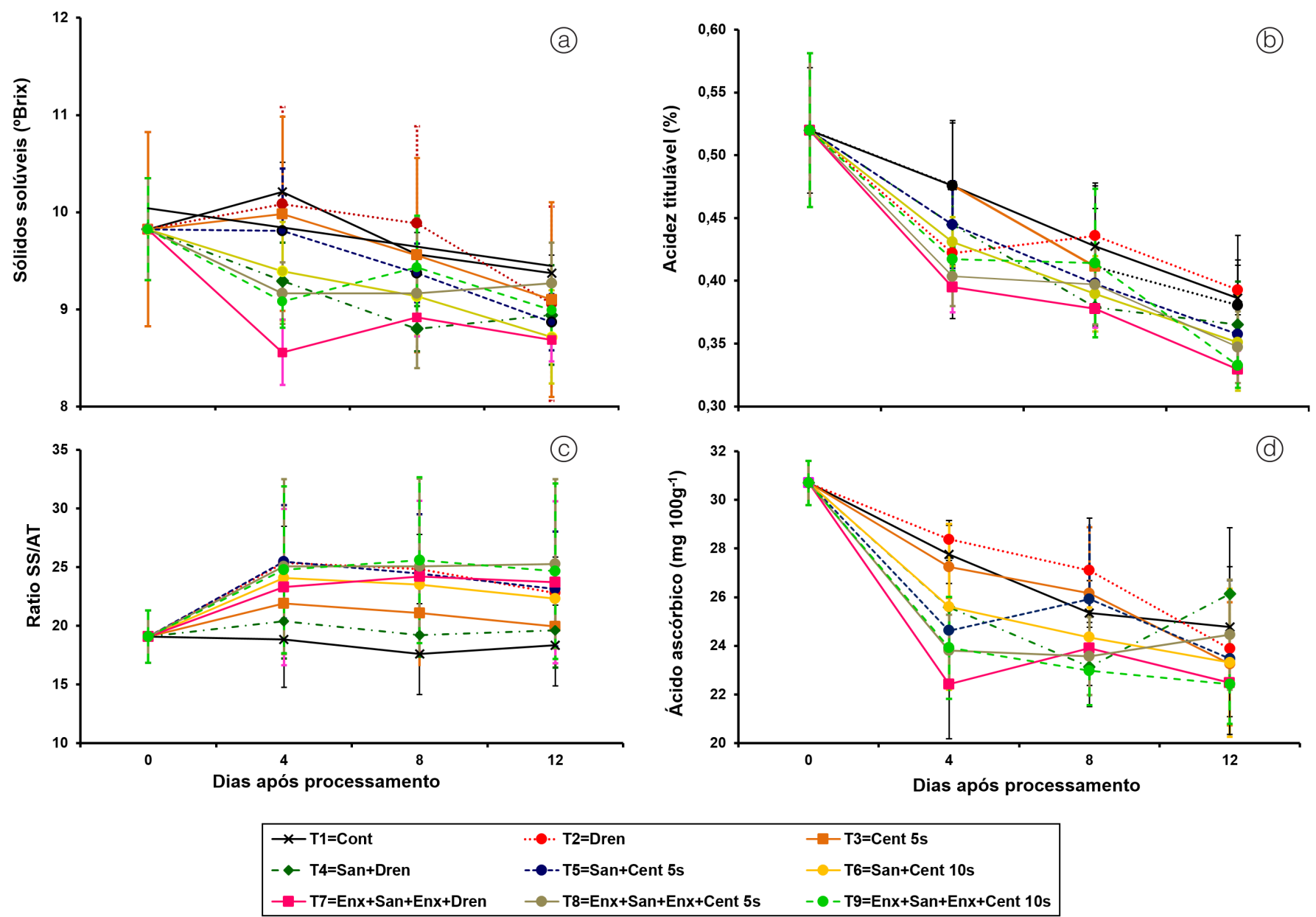

Figura 1. Características qualitativas ( $a$ = sólidos solúveis; $b=$ acidez titulável; $c=$ ratio; $d=$ ácido ascórbico) de laranja 'Pêra' minimamente processada em tiras, sanificadas com aplicações de cloro, submetidas à eliminação do excesso de líquidos e armazenadas a $5^{\circ} \mathrm{C}$. Barras verticais representam desvio padrão da média. Dren = drenagem, Cent = centrifugação, San = sanificação, Enx = enxágue.

de ácido cítrico em frutos do controle durante 12 dias de armazenamento.

Quanto ao ratio, não houve efeito dos tratamentos, do tempo de armazenamento nem da interação desses fatores $(P \geq 0,5)$ (Figura 1c). Os tratamentos que receberam duas operações de enxágue (T7 a T9) apresentaram valor médio de ratio igual a 20,7 e aqueles sem sanificação e sem enxágue (T1 e T3) apresentaram valores médios de 23,3. Pereira et al. (2014) estudaram laranja 'Valência Delta' armazenada sob condição ambiente por doze dias sendo verificado valores médios de 23,78. Segundo Pozzan e Triboni (2005), sucos com ratio entre 14 e 16 são os mais apreciados pelos consumidores devido ao equilíbrio, em termos sensoriais, entre os teores de açúcares e ácidos, sendo um importante parâmetro qualitativo, pois dá o indicativo de sabor do produto (CHITARRA; CHITARRA, 2005).

A estabilidade nos valores de ratio durante 0 armazenamento se deve ao fato de ter ocorrido redução nos teores de acidez titulável e de sólidos solúveis de forma equivalente.
Não foi verificado efeito dos tratamentos nos teores de ácido ascórbico, entretanto, ocorreu diminuição com o tempo de armazenamento na ordem de $22 \%$, em média (Figura 1d). Os teores de vitamina $\mathrm{C}$ tendem a diminuir com o amadurecimento devido à atuação direta da enzima ácido ascórbico oxidase (ascorbinase), além da oxidação e consequente transformação do ácido ascórbico em ácido 2,3-dicetogulônico (SOUZA et al., 2011). A redução do teor de ácido ascórbico durante o armazenamento também foi constatada por Shen et al. (2013) em tangerina 'Satsuma' minimamente processada.

Os tratamentos que apresentaram menor extravasamento de suco, medido pela quantidade de líquido acumulado na bandeja durante o armazenamento, foram aqueles nos quais se utilizou a centrifugação $(P \geq 0,5)$ (Figura 2). A centrifugação por 5 segundos apresentou menores valores de extravasamento que o controle e a drenagem em escorredor doméstico, sendo estatisticamente diferente em algumas comparações. A centrifugação por 10 segundos reduziu o extravasamento, quando comparado ao controle e 
Sanificação e eliminação do excesso de líquidos em laranja 'Pêra' minimamente processada IUAMOTO, M. Y. et al.

à drenagem, em todas as avaliações. A drenagem em escorredor doméstico por 1 minuto não foi efetiva na redução do extravasamento. Foi observado também que a sanificação com $100 \mathrm{mg} \mathrm{L}^{-1}$ de cloro ativo, a qual envolveu um enxague adicional (T7, T8 e T9), não afetou o extravasamento de líquidos.

Os níveis de contaminação por bactérias lácticas aumentaram ao longo do armazenamento (Tabela 1). Os tratamentos T2 e T3, em que não houve sanificação e houve eliminação de suco extravasado, apresentaram maior contaminação, da ordem de $10^{5}$ UFC g ${ }^{-1}$, no $15^{\circ}$ dia. De maneira geral, é preconizado que alimentos contendo contagens microbianas da ordem de $10^{5}-10^{6}$ são impróprios para o consumo, devido aos riscos de presença de patógenos. Possivelmente, esses tratamentos apresentaram contaminação maior do que o controle devido à maior manipulação do produto. Entretanto, todos os tratamentos que receberam algum tipo de sanificação (T4 a T9) apresentaram menor contagem de bactérias lácticas, indicando a eficiência da sanificação no controle dessas bactérias. Os dois tipos de sanificação mostraram-se eficientes no controle do crescimento de bactérias lácticas. Segundo Martín-Belloso et al. (2006), os tratamentos com imersão em soluções antimicrobianas, após o processamento de vegetais, removem os líquidos extravasados e reduzem as cargas microbianas.

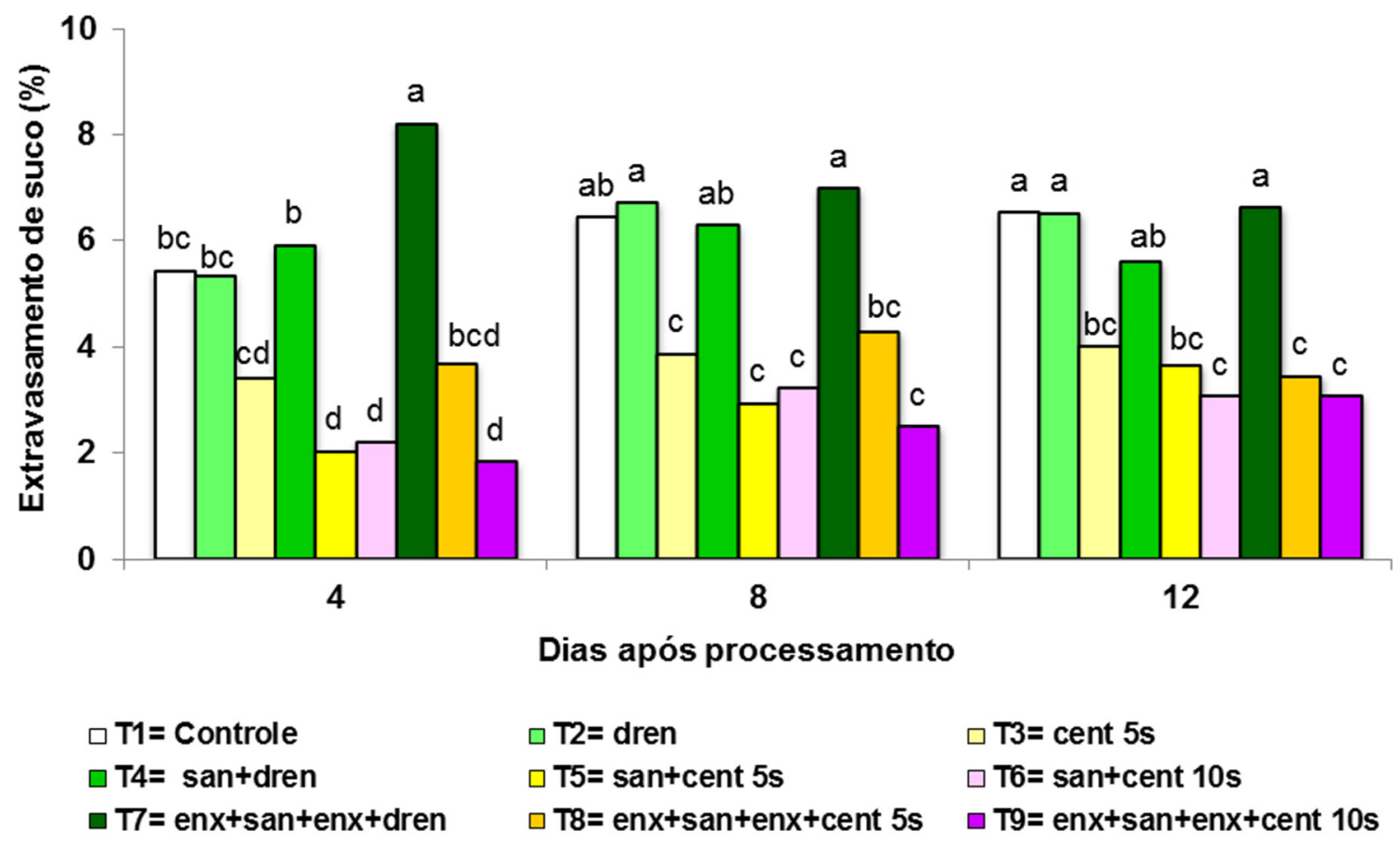

Figura 2. Extravasamento de suco de laranja 'Pêra' minimamente processada em tiras, sanificadas com aplicações de cloro, submetidas à eliminação do excesso de líquidos e armazenadas a $5^{\circ} \mathrm{C}$. Médias seguidas de mesma letra em cada dia de análise não diferem entre si, pelo teste de Tukey $(P \leq 0,05)$.

Tabela 1. Contagem total de bactérias lácticas em laranja 'Pêra' minimamente processada em tiras, sanificadas com aplicações de cloro, submetidas à eliminação do excesso de líquidos e armazenadas a $5^{\circ} \mathrm{C}$.

\begin{tabular}{lcccc}
\multicolumn{1}{c}{ Tratamento } & \multicolumn{4}{c}{ Dias após o processamento } \\
\cline { 2 - 5 } T1: Controle & $\mathbf{0}$ & $\mathbf{4}$ & $\mathbf{8}$ & $\mathbf{1 2}$ \\
T2: Dren & $3,0 \times 10$ & $<10$ & $6,0 \times 10^{3}$ & $5,2 \times 10^{3}$ \\
T3: Cent 5s & $1,0 \times 10$ & $<10$ & $7,4 \times 10^{3}$ & $1,0 \times 10^{5}$ \\
T4: San + Dren & $1,0 \times 10$ & $1,0 \times 10$ & $8,6 \times 10^{2}$ & $2,0 \times 10^{5}$ \\
T5: San + Cent 5 s & $2,0 \times 10$ & $<10$ & $2,9 \times 10^{2}$ & $2,6 \times 10^{3}$ \\
T6: San + Cent 10s & $1,5 \times 10$ & $4,6 \times 10^{4}$ & $2,5 \times 10^{4}$ & $2,6 \times 10^{3}$ \\
T7: Enx + San + Enx + Dren & $8,2 \times 10^{2}$ & $1,9 \times 10^{3}$ & $1,2 \times 10^{3}$ & $4,7 \times 10^{3}$ \\
T8: Enx + San + Enx + Cent 5s & $2,6 \times 10^{2}$ & $1,8 \times 10^{4}$ & $4,1 \times 10^{4}$ & $1,2 \times 10^{4}$ \\
T9: Enx + San + Enx + Cent 10s & $9,0 \times 10$ & $6,5 \times 10$ & $3,2 \times 10^{2}$ & $2,3 \times 10^{3}$ \\
\hline Os resutad & $2,5 \times 10$ & $4,5 \times 10$ & $7,0 \times 10$ & $6,6 \times 10^{4}$ \\
\hline
\end{tabular}

Os resultados obtidos são expressos em UFC (unidades formadoras de colônia) por g de produto. Dren = drenagem, Cent $=$ centrifugação, San = sanificação, Enx = enxágue. 
Silveira e Bertagnolli (2013) encontraram variações na ordem de $4,00 \times 10^{1}$ a $4,16 \times 10^{2}$ UFC $\mathrm{mL}^{-1}$ para bactérias láticas em diferentes amostras de suco de laranja, sendo esses valores menores do que os encontrados no presente trabalho, nos tratamentos que receberam algum tipo de sanificação (T4 a T9). Essa variação pode ocorrer pela origem do material vegetal, pelos fatores extrínsecos, como a umidade relativa e temperatura de armazenamento, e pelos seus fatores intrínsecos, como pH e teor de água (OMS-OLIU et al., 2010).

Todos os tratamentos apresentaram resultados dentro do limite aceitável em termos de contaminação por microrganismos acidúricos (bolores, leveduras e bactérias acidúricas) (Tabela 2). Verificou-se que os tratamentos em que ocorreram dois enxágues, um antes e outro após a sanificação, com a utilização de centrífuga (T8, T9), apresentaram melhores resultados. Pinheiro et al. (2009), quando avaliaram laranjas 'Pêra' minimamente processadas e armazenadas a $5^{\circ} \mathrm{C}$ durante um período de seis dias, encontraram valores de $2,8 \times 10^{2}$ ao sexto dia. Santos e Ribeiro (2006) salientam que a presença excessiva de bolores e leveduras indica manipulação inadequada, podendo ter havido falhas na limpeza das frutas e/ou manuseio realizado em condições insatisfatórias. Assim como as leveduras, as bactérias láticas são os microrganismos que melhor se adaptam ao ambiente de baixo pH e altas concentrações de açúcar, ambiente característico do suco de laranja (OLIVEIRA et al., 2006). Essas bactérias produzem $\mathrm{CO}_{2}$, ácido lático e derivados de diacetil, que induzem forte odor e gosto desagradável ao suco (RAIMUNDO et al., 2007).

Todos os tratamentos apresentaram baixa contagem de coliformes totais, chegando ao máximo a $10^{1}$ ciclo logarítmico NMP de coliformes totais por $g$ de produto (Tabela 3). Nenhum tratamento apresentou coliformes a $45^{\circ} \mathrm{C}$, atendendo à RDC no 12 de 02 de janeiro de 2001, da Agência Nacional de Vigilância Sanitária. Essa resolução estabelece o limite máximo de $500 \mathrm{NMP} \mathrm{g}^{-1}$ de coliformes termotolerantes, em frutas minimamente processadas (BRASIL et al., 2001). Donadon et al. (2004) encontraram resultados semelhantes em laranjas 'Pêra' descascadas manualmente, mecanicamente ou enzimaticamente e armazenadas a $5^{\circ} \mathrm{C}$ por 21 dias. Da mesma forma,

Tabela 2. Contagem total de microrganismos acidúricos em laranja 'Pêra' minimamente processada em tiras, sanificadas com aplicações de cloro, submetidas à eliminação do excesso de líquidos e armazenadas a $5^{\circ} \mathrm{C}$.

\begin{tabular}{lcccc}
\multicolumn{1}{c}{ Tratamento } & \multicolumn{4}{c}{ Dias após o processamento } \\
\cline { 2 - 5 } T1: Controle & $\mathbf{0}$ & $\mathbf{4}$ & $\mathbf{8}$ & $\mathbf{1 2}$ \\
T2: Dren & $1,5 \times 10$ & $3,5 \times 10$ & $1,3 \times 10^{3}$ & $5,5 \times 10^{2}$ \\
T3: Cent 5s & $3,0 \times 10$ & $3,5 \times 10$ & $3,5 \times 10^{2}$ & $9,5 \times 10^{2}$ \\
T4: San + Dren & $1,5 \times 10$ & $2,0 \times 10$ & $4,0 \times 10^{2}$ & $2,8 \times 10^{3}$ \\
T5: San + Cent 5 s & $2,0 \times 10$ & $3,5 \times 10$ & $7,5 \times 10$ & $2,1 \times 10^{3}$ \\
T6: San + Cent 10s & $4,0 \times 10$ & $3,0 \times 10$ & $1,1 \times 10^{2}$ & $1,8 \times 10^{3}$ \\
T7: Enx + San + Enx + Dren & $1,5 \times 10$ & $3,0 \times 10$ & $1,5 \times 10^{2}$ & $1,9 \times 10^{3}$ \\
T8: Enx + San + Enx + Cent 5s & $1,0 \times 10$ & $2,5 \times 10$ & $1,0 \times 10$ & $4,7 \times 10^{3}$ \\
T9: Enx + San + Enx + Cent 10s & $1,5 \times 10$ & $1,0 \times 10$ & $3,0 \times 10$ & $7,5 \times 10$ \\
\hline
\end{tabular}

Os resultados obtidos são expressos em UFC (unidades formadoras de colônia) por $\mathrm{g}$ de produto. Dren = drenagem, Cent $=$ centrifugação, San = sanificação, Enx = enxágue.

Tabela 3. Número mais provável (NMP) de coliformes totais em laranja 'Pêra' minimamente processada em tiras, sanificadas com aplicações de cloro, submetidas à eliminação do excesso de líquidos e armazenadas a $5^{\circ} \mathrm{C}$.

\begin{tabular}{lcccc}
\multicolumn{1}{c}{ Tratamento } & \multicolumn{3}{c}{ Dias após o processamento } \\
\cline { 2 - 5 } T1: Controle & $\mathbf{0}$ & $\mathbf{4}$ & $\mathbf{8}$ & $\mathbf{1 2}$ \\
T2: Dren & $<3,0$ & 3,0 & $<3,0$ & $<3,0$ \\
T3: Cent 5s & $<3,0$ & $<3,0$ & $<3,0$ & $<3,0$ \\
T4: San + Dren & $<3,0$ & $<3,0$ & $<3,0$ & $2,3 \times 10$ \\
T5: San + Cent 5 & $<3,0$ & $<3,0$ & 3,6 & $<3,0$ \\
T6: San + Cent 10s & $<3,0$ & $<3,0$ & $<3,0$ & $<3,0$ \\
T7: Enx + San + Enx + Dren & $<3,0$ & $2,3 \times 10$ & $<3,0$ & $<3,0$ \\
T8: Enx + San + Enx + Cent 5s & $<3,0$ & 3,6 & $<3,0$ & $<3,0$ \\
T9: Enx + San + Enx + Cent 10s & $<3,0$ & 3,6 & $<3,0$ & $<3,0$ \\
\hline
\end{tabular}

Os resultados obtidos representam o NMP de coliformes totais por $\mathrm{g}$ de produto. Dren = drenagem, Cent = centrifugação, San = sanificação, Enx = enxágue. 
Sanificação e eliminação do excesso de líquidos em laranja 'Pêra' minimamente processada

IUAMOTO, M. Y. et al.

Groppo et al. (2009) não encontraram contaminação de coliformes a $45^{\circ} \mathrm{C}$ em nenhuma das amostras de laranjas 'Pêra' minimamente processadas, durante 0 armazenamento.

Não houve diferença $(P \leq 0,05)$ na aparência de laranja minimamente processada submetida ou não aos processos de eliminação de excesso de líquidos. A nota média da aparência variou de 7,7 (dia 0) a 7,1 (dia 4), o que demonstra que os provadores gostaram moderadamente dos produtos mesmo quatro dias após o processamento. Isso demonstra que o processamento não causou ressecamento ou danos mecânicos às laranjas minimamente processadas. Uma das hipóteses era que o uso da centrifuga poderia ocasionar esses tipos de danos e prejudicar a aparência, o que não aconteceu neste experimento.

A eliminação do excesso de líquidos imediatamente após o processamento mínimo é importante para evitar que o suco da fruta liberado durante o processamento, bem como a água absorvida durante a sanificação e/ou enxágue, sejam drenados durante o armazenamento, ocasionando acúmulo no interior das embalagens.

\section{Conclusões}

A centrifugação por 10 segundos em centrífuga doméstica $(760 \times \mathrm{g})$ reduziu o acúmulo de líquidos nas bandejas durante o armazenamento refrigerado e manteve a aparência da laranja 'Pêra' minimamente processada. A drenagem por 1 minuto não foi eficiente na redução do acúmulo de líquidos nas bandejas.

A drenagem e a centrifugação aumentaram os níveis de contagem microbiana em relação ao controle, mas quando foi usada a sanificação em combinação com estes tratamentos houve redução na microbiota contaminante.

\section{Agradecimentos}

À Fundação de Amparo à Pesquisa do Estado de São Paulo (FAPESP) pela concessão da bolsa de mestrado (Proc. 2006/05468-7) à primeira autora.

\section{Referências}

ARRUDA, M. C. D.; JACOMINO, A. P.; PINHEIRO, A. L.; RIBEIRO, R. V.; LOCHOSKI, M. A.; MOREIRA, R. C. Hydrothermal treatment favors peeling of 'Pera' sweet orange fruit and does not alter quality. Scientia Agricola, Piracicaba, v. 65, n. 2, p. 151-156, 2008. http://dx.doi.org/10.1590/S0103-90162008000200007.

ARRUDA, M.; JACOMINO, A. P.; TREVISAN, M. J.; JERONIMO, E. M.; MORETTI, C. L. Atmosfera modificada em Iaranja 'Pêra' minimamente processada. Bragantia, Campinas, v. 70, n. 3, p. 664-671, 2011. http://dx.doi.org/10.1590/S000687052011000300023.
BRASIL. Agência Nacional de Vigilância Sanitária. Resolução RDC no 12, de 02 de janeiro de 2001. Aprova o Regulamento Técnico sobre padrões microbiológicos para alimentos. Diário Oficial [da] República Federativa do Brasil, Brasília, DF, 10 jan. 2001.

CARVALHO, C. R. L.; MANTOVANI, D. M. B.; CARVALHO, P. R. N.; MORAES, R. M. M. Análise química de alimentos. Campinas: ITAL, 1990. $121 \mathrm{p}$.

CHITARRA, M. I. F.; CHITARRA, A. B. Qualidade pós-colheita. In: CHITARRA, M. I. F.; CHITARRA, A. B. Pós-colheita de frutas e hortaliças: fisiologia e manuseio. 2. ed. Lavras: UFLA, 2005. p. $541-753$.

DEL CARO, A.; PIGA, A.; VACCA, V.; AGABBIO, M. Changes of flavonoids, vitamin $C$ and antioxidant capacity in minimally processed citrus segments and juices during storage. Food Chemistry Barking, Barking, v. 84, n. 1, p. 99-105, 2004. http:// dx.doi.org/10.1016/S0308-8146(03)00180-8.

DONADON, J. R.; DURIGAN, J. F.; SOUZA, B. S.; TEIXEIRA, G. H. A.; SANCHES, J. Efeito do tipo de descasque e da temperatura de armazenamento na qualidade de laranjas 'Pêra' minimamente processadas. Revista Brasileira de Fruticultura, Jaboticabal, v. 26, n. 3, p. 419-423, 2004. http://dx.doi.org/10.1590/S010029452004000300012.

FERREIRA, V. L. P.; ALMEIDA, T. C. A. V.; PETTINELLI, M. L. C. V.; SILVA, M. A. A. P.; CHAVES, J. B. P.; BARBOSA, E. M. $M$. Análise sensorial: testes discriminativos e afetivos. Campinas: SBCTA, 2000. 127 p.

FRANCIS, G. A.; GALLONE, A.; NYCHAS, G. J.; SOFOS, J. N.; COLELLI, G.; AMODIO, M. L.; SPANO, G. Factors affecting quality and safety of fresh-cut produce. Critical Reviews and Food Science and Nutrition, Filadélfia, v. 52, n. 7, p. 595-610, 2012. http://dx.doi.org/10.1080/10408398.2010.5036 85. PMid:22530712.

GROPPO, V. D.; SPOTO, M. H. F.; GALLO, C. R.; SARMENTO, S. B. S. Efeito do cloreto de cálcio e da película de alginato de sódio na conservação de laranja 'Pera' minimamente processada. Ciência e Tecnologia de Alimentos, Campinas, v. 29, n. 1, p. 107-113, 2009. http://dx.doi.org/10.1590/S010120612009000100017.

JACOMINO, A. P.; ARRUDA, M. C. Processamento mínimo de frutas cítricas. In: MORETTI, C. L. (Ed.). Manual de processamento mínimo de frutas e hortaliças. Brasília: Embrapa Hortaliças; SEBRAE, 2008. cap. 15, p. 283-294.

LATIMER JUNIOR, G. W. (Ed.). Official methods of analysis of the Association of Official Analytical Chemists. 19th. ed. Gaithersburg: AOAC, 2012. 3000 p.

MARTÍN-BELLOSO, O.; SOLIVA-FORTUNY, R.; OMS-OLIU, G. Fresh-cut fruits. In: $\mathrm{HUI}, \mathrm{Y}$. H. (Ed.). Handbook of fruits and fruit processing. Oxford: Blackwell Publishing, 2006. p. 129-144. 
Sanificação e eliminação do excesso de líquidos em laranja 'Pêra' minimamente processada IUAMOTO, M. Y. et al.

MARTÍN-DIANA, A. B.; RICO, D.; FRÍAS, J. M.; BARAT, J. M.; HENEHAN, G. T. M.; BARRY-RYAN, C. Calcium for extending the shelf life of fresh whole and minimally processed fruits and vegetables: a review. Trends in Food Science and Technology, Cambridge, v. 18, n. 4, p. 210-218, 2007.

OliveIRA, J. C.; SETTI-PERDIGÃO, P.; SIQUEIRA, K. A. G.; SANTOS, A. C.; MIGUEL, M. A. L. Características microbiológicas do suco de laranja in natura. Ciência e Tecnologia de Alimentos, Campinas, v. 26, n. 2, p. 241-245, 2006. http://dx.doi.org/10.1590/S0101-20612006000200002.

OMS-OLIU, G.; ROJAS-GRAU, M. A.; GONZÁLEZ, L. A.; VARELA, P.; SOLIVA-FORTUNY, R.; HERNANDO, M. I. H.; MUNUERA, I. P.; FISZMAN, S.; MARTÍN-BELLOSO, O. Recent approaches using chemical treatments to preserve quality of fresh-cut fruit: a review. Postharvest Biology and Technology, Amsterdam, v. 57, n. 3, p. 139-148, 2010. http://dx.doi.org/10.1016/j. postharvbio.2010.04.001.

PEREIRA, G. S.; MACHADO, F. L. C.; COSTA, J. M. C. Aplicação de recobrimento prolonga a qualidade pós-colheita de laranja 'Valência Delta' durante armazenamento ambiente. Revista Ciência Agronômica, Fortaleza, v. 45, n. 3, p. 520-527, 2014. http://dx.doi.org/10.1590/S1806-66902014000300012.

PINHEIRO, A. L.; JACOMINO, A. P.; ARRUDA, M. C. D.; RIBEIRO, R. V.; KLUGE, R. A.; TREVISAN, M. J. Peeling of 'Pera' sweet orange related to the duration of the hydrothermal treatment. Ciência Rural, Santa Maria, v. 39, n. 6, p. 1857-1863, 2009. http://dx.doi.org/10.1590/S0103-84782009000600034.

POZZAN, M.; TRIBONI, H. R. Colheita e qualidade do fruto. In: MATTOS JÚNIOR, D.; DE NEGRI, J. D.; PIO, R.; POMPEU JUNIOR, J. (Ed.). Citros. Campinas: IAC; Fundag, 2005. cap. 26, p. 801-822.

RAIMUNDO, E.; KRÜGER, R. L.; DI LUCCIO, M.; CICHOSKI, A. J. Cor, viscosidade e bactérias lácticas em suco de laranja pasteurizado e submetido ao efeito da luz durante o armazenamento. Alimentos Nutrição, Araraquara, v. 18, n. 4, p. 449-456, 2007.

RINALDI, M. M.; BENEDETTI, B. C.; CALORE, L. Efeito da embalagem e temperatura de armazenamento em repolho minimamente processado. Ciência e Tecnologia de Alimentos, Campinas, v. 25, n. 3, p. 480-486, 2005. http://dx.doi. org/10.1590/S0101-20612005000300015.
SANTOS, J. S.; OLIVEIRA, M. B. P. P. Revisão: alimentos frescos minimamente processados embalados em atmosfera modificada. Brazilian Journal of Food Technology, Campinas, v. 15, n. 1, p. 1-14, 2012. http://dx.doi.org/10.1590/S198167232012000100001.

SANTOS, J.; RIBEIRO, G. A. Avaliação microbiológica de sucos de laranja "in natura", comercializados na cidade de Pelotas, RS. Higiene Alimentar, São Paulo, v. 20, n. 138, p. 104-107, 2006.

SANTOS, T. B. A.; SILVA, N.; JUNQUEIRA, V. C. A.; PEREIRA, J. L. Microrganismos indicadores em frutas e hortaliças minimamente processadas. Brazilian Journal Food and Technology, Campinas, v. 13, n. 2, p. 141-146, 2010. http:// dx.doi.org/10.4260/BJFT2010130200019.

SHEN, Y.; SUN, Y.; QIAO, L.; CHEN, J.; LIU, D.; YE, X. Effect of UV-C treatments on phenolic compounds and antioxidant capacity of minimally processed Satsuma mandarin during refrigerated storage. Postharvest Biology and Technology, Leuven, v. 76, p. 50-57, 2013. http://dx.doi.org/10.1016/j. postharvbio.2012.09.006.

SILVA, M. Z. T.; GUERRA, N. B. Avaliação das condições de frutos minimamente processados. Higiene Alimentar, São Paulo, v. 17, n. 111, p. 29-36, 2003.

SILVA, N.; JUNQUEIRA, V. C. A.; SILVEIRA, N. F. A.; TANIWAKI, M. H.; SANTOS, R. F. S.; GOMES, R. A. R. Manual de métodos de análise microbiológica de alimentos. 3. ed. São Paulo: Livraria Varela, 2007. 552 p.

SILVEIRA, M. L. R.; BERTAGNOLLI, S. M. M. Avaliação microbiológica e das condições higiênico-sanitárias de comercialização de sucos de laranja in natura. Alimentos e Nutrição, Araraquara, v. 23, n. 3, p. 461-466, 2013.

SOUZA, M. L.; MORGADO, C. M. A.; MARQUES, K. M.; MATTIUZ, C. F. M.; MATTIUZ, B. H. Pós-colheita de mangas 'Tommy Atkins' recobertas com quitosana. Revista Brasileira de Fruticultura, Jaboticabal, v. 33, n. 1, p. 337-343, 2011. Volume especial.

VITTI, M. C. D.; KLUGE, R. A.; GALlO, C. R.; MORETTI, C. L.; JACOMINO, A. P. Efeito do momento de sanitização sobre atributos fisico-químicos e microbiológicos de beterrabas minimamente processadas. Horticultura Brasileira, Brasília, v. 22, n. 4, p. 718-721, 2004. http://dx.doi.org/10.1590/S010205362004000400010 . 